\title{
Prescribing by general practitioners after an osteoporotic fracture
}

\author{
David J Torgerson, Paul Dolan
}

\begin{abstract}
Objectives-Osteoporosis is a major cause of morbidity and cost. Patients sustaining one osteoporotic fracture are at increased risk of having another fracture. The objective of this study was to examine the use of "bone drugs" for the prevention of further osteoporotic fractures among patients who have had a "typical" osteoporotic fracture.

Methods-This study took a random sample of 300 women aged 50 and over who had sustained either a vertebral, hip or Colles fracture in 1995 from the General Practice Research Database (GPRD) and compared their use of bone drugs with 300 age and practice matched controls.

Results-Compared with age and practice matched control patients only vertebral fracture patients showed a statistically significant increase in the use of bone drugs in the year after fracture $(39 \%$ and $2 \%$ for cases and controls respectively; $95 \%$ CI of difference $27 \%$ to $47 \%$ ). Etidronate was the most commonly used compound.

Conclusion-The majority of patients sustaining an osteoporotic fracture are not prescribed any pharmaceutical agents for the secondary prevention of fracture one year after a primary fracture.

(Ann Rheum Dis 1998;57:378-379)
\end{abstract}

Centre for Health

Economics, University of York, York YO1 5DD

Correspondence to: David Torgerson.

Accepted for publication 27 March 1998

Osteoporotic fractures are an important cause of morbidity, mortality, and cost to society. ${ }^{1}$ There are a number of pharmaceutical treatments now available that have been shown in randomised trials to prevent fractures. Most studies have been undertaken to prevent new vertebral fractures among patients with a prevalent vertebral fracture ${ }^{2-4}$; but more recently trials have shown benefit of calcium and

Table 1 Use of bone drugs by fracture type

\begin{tabular}{llll}
\hline & \multicolumn{2}{l}{ Number using bone drugs } \\
\cline { 2 - 4 } & Cases & Controls & $\begin{array}{l}\text { Per cent difference (95\% } \\
\text { confidence intervals) }\end{array}$ \\
Fracture type & & & \\
\hline Hip & 2 & 3 & $1(-5$ to 3$)$ \\
$\quad$ Year before fracture (1994) & 9 & 3 & $6(-0.5$ to 12$)$ \\
$\quad$ Year of fracture (1995) & 4 & 4 & $0(-5$ to 5$)$ \\
$\quad$ Year after fracture (1996) & 7 & 5 & $2(-5$ to 9$)$ \\
Wrist & 7 & 5 & $2(-5$ to 9$)$ \\
$\quad$ Year before fracture (1994) & 5 & 6 & $1(-7$ to 5$)$ \\
$\quad$ Year of fracture $(1995)$ & 10 & 5 & $5(-2$ to 12$)$ \\
$\quad$ Year after fracture $(1996)$ & 41 & 6 & $35(24$ to 46$)$ \\
Vertebral & 39 & 2 & $37(27$ to 47$)$ \\
$\quad$ Year before fracture (1994) & & & \\
$\quad$ Year of fracture $(1995)$ & &
\end{tabular}

vitamin $\mathrm{D}$ in combination and alendronate in preventing hip and other fractures..$^{5-7}$

In this study we examined the use of four groups of pharmaceutical compounds by general practitioners in the United Kingdom, which have been shown to reduce the incidence of fractures after the diagnosis of an osteoporotic facture.

\section{Methods}

We took an anonymised random sample of 600 records from the General Practice Research Database $^{8}$ (GPRD) with 100 cases of hip, wrist, and vertebral fracture diagnosed in 1995 and matched them, by age and practice, with an equivalent number of healthy controls. The GPRD has previously been shown to have high level of validity at ascertaining medical events; for example, one study has shown that over $90 \%$ of prescriptions are recorded on the database. $^{9}$

We identified four types of drugs affecting bone metabolism that might be prescribed by GPs for the prevention of further fractures. These were: hormone replacement therapy $(\text { HRT })^{3}$; calcium supplements with or without vitamin $\mathrm{D}^{6} 7$; bisphosphonates (etidronate and alendronate $)^{245}$; and calcitonin. The records of patients were examined for the prescriptions of the four drug types the year before fracture, the year of fracture, and the year after fracture.

\section{Results}

The mean (SD) ages of the hip, wrist, and vertebral fracture patients were 77.52 (8.17), 69.00 (9.43), and 72.88 (9.30) years respectively for the cases and 77.51 (8.15), 69.00 (9.93), and 72.88 (9.25) years for the relevant controls, which shows that the cases and controls were well matched for age. Table 1 shows that, compared with controls, only patients with a diagnosed vertebral fracture had significantly different use of drugs affecting bone metabolism either during the year of fracture or in the year after fracture. For the 39 patients with a diagnosed vertebral fracture who were still using one of the bone drugs in the year after fracture seven were taking HRT, 10 were prescribed calcium and vitamin $\mathrm{D}$, and 27 were prescribed etidronate. Five patients took a combination of compounds and no patient was prescribed calcitonin or alendronate. The two control patients were both using HRT. There were no age differences between those women using calcium and etidronate and the nonusers (75.36 and 72.70 years respectively, $\mathrm{p}=$ $0.25)$; but HRT users were significantly younger $(62.00$ years, $\mathrm{p}<0.001)$. 


\section{Discussion}

In this study, the only osteoporotic fracture associated with increased use of drugs for the secondary prevention of further fractures was vertebral. As many vertebral fractures are undiagnosed the fractures identified in this study are probably the more severe symptomatic ones. Despite this, however, the majority of vertebral fracture patients did not receive any of the drug treatments that have been shown to reduce further vertebral fractures. Although some patients may have contraindications to treatment it is unlikely to be as many as $59 \%$ who were not prescribed treatment in the year of fracture. Our data, however, do not allow us to determine whether other antifracture measures were undertaken (for example, lifestyle advice) or indeed, whether patients were taking over the counter medicines such as calcium supplements. Although drugs other than the ones identified in our study are used for osteoporosis prevention, with the exception of alendronate, they are probably confined to a few specialised secondary care centres. With respect to alendronate it was not lauched in the UK until late 1995 and then not widely used outside specialist centres. Therefore, it is unsurprising given that the fractures occurred in 1995 that no patient was prescribed this compound.

Severe vertebral fracture is not only a disabling condition ${ }^{10}$ but is an indication of generalised osteoporosis. Such patients are at increased risk of hip and other fractures ${ }^{11}$; hence, it is important some secondary preventive measures are taken in such patients. For other types of fracture the evidence base for prevention has not been as secure as that for preventing vertebral fractures. However, a recently published trial suggests that a bisphos- phonate is effective in reducing vertebral and appendicular fractures (including hip) among women with a prevalent vertebral fracture. ${ }^{5}$ Furthermore, calcium and vitamin D may have a role in reducing appendicular fractures ${ }^{6} 7$

In conclusion, then, fractures of the hip and wrist are not associated with increased use of drugs for secondary prevention and only a minority of vertebral fracture patients are prescribed anti-fracture medication.

Funding: Eli Lilly Pharmaceuticals funded the authors to undertake a cost of illness study for which these data were originally used. We thank the three anonymous referees for helpful comments.

1 Barlow DH. Advisory group on osteoporosis. London: Department of Health, 1994

2 Storm T, Thamsborg G, Steinich T, Genant HK, Sorensen $\mathrm{OH}$. Effect of intermittent cylical etidronate therapy on one mass and fracture rate in women with postmentopaual osteoporosis. N Engl J Med 1990;322:1265-71.

3 Lufkin EG, Wahner HW, O'Fallon WM, Hodgson S, Kotowitz MA, et al. Treatment of postmenopausal osteoporosis with transdermal estrogen. Ann Intern Med 1992;117:1-9.

4 Liberman UA, Weiss SR, Broll J, Minne HW, Quan H, Bell $\mathrm{NH}$, et al. Effect of oral alendronate on bone mineral density and the incidence of fractures in postmenopausal osteoporosis. N Engl J Med 1995;333:1437-43.

5 Black DM, Cummings SR, Karpf DB, Cauley JA, Thompson DE, Nevitt MC, et al. Randomised trial of effect of alendronate on risk of fracture in women with existing vertebral fractures. Lancet 1996;348:1535-41.

6 Chapuy MC, Arlott ME, Duboeuff F, Brun J, Crouzet B, Arnaud S, et al. Vitamin D3 and calcium to prevent hip fractures in elderly women. N Engl J Med 1992;327:163742 .

7 Dawson-Hughes B, Harris SS, Krall EA, Dallal GE. Effect of calcium and vitamin D supplementation on bone density in men and women 65 years of age or older. N Engl J Med 1997;337:670-6.

8 Walley T, Mantgani A. The UK General Practice Research Database. Lancet 1997;350:1097-9.

9 Jick H, Jick SS, Derby LE. Validation of information recorded on general practitioner based computerised data resource in United Kingdom. BMJ 1991;302:766-8.

10 Greendale GA, Barrett-Connor E, Ingles S, Haile R. Late physical and functional effects of osteoporotic fractures in women: The Rancho Bernado Study. J Am Geriatr Soc 1995;43:955-61.

11 Burger H, van Daele PLA, Algra D, Hofman A, Grobbee of non-vertebral fractures. BMJ 1994;309:991-2. 